\title{
The role of insulin therapy and glucose normalisation in patients with acute coronary syndrome
}

\author{
J. A. Lipton • A. Can · S. Akoudad • M. L. Simoons
}

Published online: 18 January 2011

(C) The Author(s) 2011. This article is published with open access at Springerlink.com

\begin{abstract}
Patients with acute myocardial infarction (AMI) and diabetes mellitus, as well as patients admitted with elevated blood glucose without known diabetes, have impaired outcome. Therefore intensive glucose-lowering therapy with insulin (IGL) has been proposed in diabetic or hyperglycaemic patients and has been shown to improve survival and reduce incidence of adverse events. The current manuscript provides an overview of randomised controlled trials investigating the effect of IGL. Furthermore, systematic glucose-insulin-potassium infusion (GIK) has been studied to improve outcome after AMI. In spite of positive findings in some early studies, GIK did not show any beneficial effects in recent clinical trials and thus this concept has been abandoned. While IGL targeted to achieve normoglycaemia improves outcome in patients with AMI, achievement of glucose regulation is difficult and carries the risk of hypoglycaemia. More research is needed to determine the optimal glucose target levels in AMI and to investigate whether computerised glucose protocols and continuous glucose sensors can improve safety and efficacy of IGL.
\end{abstract}

Keywords Acute coronary syndrome - Unstable angina pectoris · Myocardial infarction · Hyperglycemia - Glucose · Insulin $\cdot$ Potassium $\cdot$ Clinical protocols

\section{Introduction}

Diabetes is common in patients presenting with an acute coronary syndrome (ACS). Furthermore, hyperglycaemia or

J. A. Lipton $(\varangle) \cdot$ A. Can $\cdot$ S. Akoudad $\cdot$ M. L. Simoons

Department of Cardiology, Erasmus Medical Center,

s-Gravendijkwal 230,

3015 CE Rotterdam, the Netherlands

e-mail: j.lipton@erasmusmc.nl impaired glucose tolerance is present in more than a third of ACS patients without known diabetes [1]. Both in patients with diabetes and in non-diabetics with evolving myocardial infarction (AMI) hyperglycaemia is associated with increased in-hospital death (RR 1.7 [1.2-2.4]), and with other adverse events including cardiac arrest, cardiogenic shock and pulmonary oedema [2-4]. Also in patients with stable coronary artery disease, diabetes is associated with a higher 1-year incidence of death and cardiovascular events (13.0\% vs. 5.6\%) [5].

Hyperglycaemia has been recognised both as mediator and as marker of adverse outcomes in ACS patients. Elevated glucose levels can reflect the severity of disease when it results from elevated catecholamine and cortisol levels. Also, the presence of additional conditions such as infection or sepsis may further disturb carbohydrate metabolism and glucose levels. Insulin resistance due to pre-existent diabetes (recognised or unrecognised) amplifies the stress-related effects on glucose levels. In patients with AMI, hyperglycaemia is associated with higher free fatty acid concentrations [6], insulin resistance and impaired myocardial glucose metabolism, resulting in an increased oxygen consumption and consequently a more severe ischaemic state [7]. Insulin limits the detrimental effects of hyperglycaemia by reducing glucose levels. Also, insulin may improve myocardial glucose utilisation by reducing free fatty acid concentrations due to its inhibitory effect on lypolysis [7]. Finally, insulin has antithrombotic, anti-inflammatory and vasodilative properties [8-10].

In critically ill patients insulin therapy improves outcome [11-13]. Also in hyperglycaemic patients with AMI, glucose-lowering insulin therapy is associated with reduced mortality at 7 and 30 days when compared with standard treatment $(11.6 \%$ and $15.8 \%$ vs. $16.5 \%$ and $22.1 \%$, respectively) [14]. Similarly, in patients with stable coronary disease, treatment of hyperglycaemia is associated with a reduction in cardiovascular events at 1 year (HR 0.22 [0.05-0.97]) [15]. The results of these observa- 
tional studies have led to three randomised controlled trials investigating the effect of intensive glucose-lowering insulin therapy (IGL) on outcomes in hyperglycaemic diabetic, and non-diabetic patients admitted with AMI $[11,16,17]$.

A different concept of insulin treatment in ACS was tested in the form of a glucose-insulin-potassium infusion (GIK). This treatment was developed as a 'polarising solution' to prevent arrhythmias and avoid further ischaemic damage in unselected patients with acute myocardial infarction [18, 19]. From 1960 onwards, different (randomised) trials have been done, utilising GIK infusion and later insulin therapy in ACS patients.

The purpose of this manuscript is to provide an overview of the evidence for implementing IGL or GIK in ACS patients by comparing trials with regard patient characteristics, reperfusion treatment, study protocols and outcomes.

\section{Methods}

A systematic PubMed search was performed to identify all clinical trials with insulin (both IGL and GIK were included) in patients with unstable angina or AMI. $\mathrm{MeSH}$ terms used were 'myocardial infarction', 'angina, unstable', 'insulin' and 'glucose'. All abstracts were screened; when fitting the criteria the manuscript was obtained and reviewed. Other studies were included through references. Hazard ratios and confidence intervals for short-term mortality were recalculated to facilitate comparisons.

\section{Results and Discussion}

The initial query gave 356 hits. After screening, 20 GIK and three IGL trials were reviewed. For the GIK studies performed before 1994, a review article was selected that provided a thorough analysis of these trials. From 1994 to 2004, six GIK trials were published that included patients with AMI or unstable angina. These differed from the prior studies in that the included patients received reperfusion therapy. The three IGL studies are discussed separately and in more detail as they are more relevant to current clinical practice. An overview of the study characteristics is given in Table 1. Outcomes and glycaemic parameters are provided in Table 2 .

\section{Glucose Normalisation}

In the prethrombolytic era, two observational studies using historical controls showed inconsistent results for the beneficial effect of insulin treatment in diabetic AMI patients. Clark et al. reported a reduced incidence of arrhythmias and death in the patients treated with IGL [20]. In contrast, Gwilt et al. did not find a difference in mortality in diabetics treated with an insulin infusion protocol, though they did find a higher mortality rate in diabetic vs. non-diabetic AMI patients [21].

Between 1990 and 2004 three randomised controlled trials were performed including patients with AMI and known diabetes or hyperglycaemia at admission [11, 16, 17]. Patients from Europe [11, 16] and Australia [17] were included; study size varied from 240 to 1253 patients. IGL was administered via an intravenous insulin regime for at least $24 \mathrm{~h}$ to achieve glucose levels of $<10.0 \mathrm{mmol} / \mathrm{l}$. The DIGAMI studies included a 3 month subcutaneous insulin regimen as well. Admission glucose levels ranged from 10.8 to $15.7 \mathrm{mmol} / \mathrm{l}$. At $24 \mathrm{~h}$, glucose levels were reduced in both IGL and control groups, but more so in the IGL groups. The difference in glucose levels between patients allocated to IGL or conventional treatment ranged from $2.1 \mathrm{mmol} / 1$ (DIGAMI-1) to $0.7 \mathrm{mmol} / \mathrm{l}$ (the average over $24 \mathrm{~h}$ in $\mathrm{HI}-5$ ). Long-term mortality was lower in two of the three studies, but this was statistically significant in DIGAMI-1 only. However, mortality was lower in the control group of DIGAMI-2.

DIGAMI-1 [11] was the first randomised trial for IGL, and showed a $29 \%$ relative reduction $(18.6 \%$ vs. $26.1 \%)$ in 1-year mortality among hyperglycaemic or diabetic AMI patients treated with IGL during the first $12 \mathrm{~h}$ and continued subcutaneously for 3 months. Interestingly, about half of this difference in mortality was achieved in the first 3 months, while additional benefit occurred at longer follow-up. In this trial, about half of the patients received thrombolytic therapy. The target for IGL in DIGAMI was a glucose level of 7-10 mmol/1.

The second DIGAMI [16] trial was designed to verify whether normalisation of serum glucose (target 5$7 \mathrm{mmol} / \mathrm{l}$ for fasting glucose) would further improve outcome. Three treatment regimens were compared: IGL $24 \mathrm{~h}$, IGL $24 \mathrm{~h}$ continued for 3 months subcutaneously and a control group. No significant difference was seen in survival in the IGL groups compared with conventional management $(P=0.203)$ while, unexpectedly, the highest survival rate was observed in the control group.

The discrepancy between the first and second DIGAMI can be attributed to several factors. Most importantly, patients were less ill and admission glucose levels were lower in DIGAMI-2 than in DIGAMI-1 and the investigators did not succeed in normalising glucose levels in the IGL groups. The difference in glucose levels vs. controls was $2.1 \mathrm{mmol} / \mathrm{l}$ in DIGAMI-1 and only $0.9 \mathrm{mmol} / \mathrm{l}$ in DIGAMI-2. Additionally, in DIGAMI-2, 14\% of the patients in the control group also received insulin infusion during hospital admission, the overall admission glucose levels were lower and reperfusion treatment was given more often ( $78 \%$ vs. $50 \%)$. 
Table 1 Overview of randomised controlled trials

\begin{tabular}{|c|c|c|c|c|}
\hline Study name & Inclusion & $\begin{array}{l}\text { \% PCI/thrombolysis/ } \\
\text { CABG/none }\end{array}$ & Location & Period \\
\hline Fath et al. [31] & $\begin{array}{l}\text { Meta-analysis of nine RCTs implementing } \\
\text { GIK in AMI }\end{array}$ & 0/1/0/99 & Multicentre, international & 1965-1987 \\
\hline Pol-GIK & $\begin{array}{l}\text { Chest pain and ECG changes }<24 \mathrm{~h}, \\
\text { IDDM excluded }\end{array}$ & $0 / 60 / 0 / 40$ & Multicentre (16), Poland & $1994-1995$ \\
\hline Krljanac et al. [32] & STEMI patients & $0 / 100 / 0 / 0$ & Belgrade, Serbia & $2000-2001$ \\
\hline GIPS I & AMI presenting within $24 \mathrm{~h}$ of symptoms & $91 / 0 / 4 / 5$ & Zwolle, the Netherlands & $1998-2001$ \\
\hline GIPS II & STEMI $<24 \mathrm{~h}$, heart failure excluded & $93 / 2 / 0 / 5$ & Multicentre (7), the Netherlands & 2003-2004 \\
\hline Create-ECLA & STEMI presenting within $12 \mathrm{~h}$ of symptom onset & $9 / 74 / 0 / 7$ & Multicentre (470), international $(>10)$ & 1998-2004 \\
\hline OASIS 6 & STEMI presenting within $24 \mathrm{~h}$ (later $12 \mathrm{~h}$ ) & $31 / 45 / 0 / 24$ & Multicentre (447) international (41) & 2003-2004 \\
\hline DIGAMI I & $\begin{array}{l}\text { AMI }<24 \mathrm{~h} \text { and diabetes or glucose } \\
\text { of }>11.0 \mathrm{mmol} / 1\end{array}$ & $0 / 50 / 0 / 50$ & Multicentre (19), Sweden & $1990-1993$ \\
\hline DIGAMI II & AMI $<24 \mathrm{~h}$, type 2 diabetes or $>11.0 \mathrm{mmol} / 1$ & $42 / 36 / 0 / 22$ & $\begin{array}{l}\text { Multicentre (44) International } \\
(6, \text { Europe })\end{array}$ & $1998-2003$ \\
\hline HI-5 & AMI $<24 \mathrm{~h}$ with diabetes or $>7.8 \mathrm{mmol} / 1$ & $35 / 32 / 0 / 33$ & Multicentre (6) Australia & 2001-2004 \\
\hline
\end{tabular}

$R C T$ randomised controlled trial, IDDM insulin dependent diabetes mellitus, AMI acute myocardial infarction, STEMI ST-elevation myocardial infarction, GIK glucose-insulin-potassium infusion, $E C G$ electrocardiogram

The more recent HI-5 study [17] did find a lower mortality at 3 and 6 months in favour of IGL, which is consistent with DIGAMI-1, although this was not statistically significant. There was also a lower incidence of heart failure during admission $(12.7 \%$ vs. $22.8 \% ; P=0.04)$ and reinfarction within 3 months $(2.4 \%$ vs. $6.1 \% ; P=0.05)$ in the insulintreated group. The mortality rates in the HI-5 study were markedly lower than those in the DIGAMI studies. This can be explained by the younger population (62 vs. 68 years), by inclusion of non-diabetic subjects $(48 \%)$, increased use of reperfusion therapy (67\% vs. $50 \%)$ and overall improved care in the more recent time period (2001-2004 vs. 1990-1993) of the HI-5 vs. the DIGAMI study.

\section{Glucose Target Range and Hypoglycaemia}

The results of DIGAMI-2 illustrate the difficulty in regulating glucose levels and achieving 'optimal' target ranges. DIGAMI started insulin infusion in patients with a glucose level of $11 \mathrm{mmol} / \mathrm{l}$ or higher, and aimed for values between 7 and $10 \mathrm{mmol} / \mathrm{l}$. After the landmark trial from Leuven [13], in an intensive care population, found a $10.4 \%$ absolute difference in mortality in favour of IGL targeted to $4.4-6.1 \mathrm{mmol} / \mathrm{l}$, many subsequent trials used similar targets. However the later trials were unable to reproduce the results [22]. The most recent NICE-SUGAR trial even reported a higher incidence of death, similar to DIGAMI-2. Since hypoglycaemic episodes occurred more frequently in the IGL group, this resulted in a modification in the ACC/AHA guidelines [23] to use $10 \mathrm{mmol} / \mathrm{l}$ as a threshold for initiating treatment in STEMI patients. The ESC guidelines [24] still mention a target range of 5 to
$7.8 \mathrm{mmol} / \mathrm{l}$; however, these were established before the NICE-SUGAR results appeared.

The fear for hypoglycaemia in certain IGL protocols seems grounded, and prevention requires frequent measurement or a wider glucose target range. Meijering et al. [25] evaluated insulin protocols in 24 studies (including six with AMI patients). The best results were found using a dynamic scale protocol for continuous intravenous insulin infusion, combined with frequent blood glucose measurement and taking into account changes in glucose levels rather than single values.

Compliance with any insulin protocol is difficult to achieve. Computerised insulin protocols exist [26-28] and can improve protocol compliance and glycaemic regulation; however, frequent measurements are required. More recently, a closed loop system for glycaemic regulation in the intensive care unit was developed using a continuous glucose sensor [29]. This, however, requires further testing. Also, the reliability of continuous glucose sensors needs further improvement [30] and validation is necessary in the AMI patient population, particularly in patients with heart failure and hypoperfusion of the skin and subcutaneous tissues.

\section{Glucose-Insulin-Potassium Therapy}

A meta-analysis by Fath et al. [31] of GIK trials done in the pre-reperfusion therapy era (before 1988) showed a lower mortality in the GIK-treated group than in controls $(16 \%$ vs. $21 \% ; P=0.004)$. However, in later trials that included patients receiving reperfusion therapy (either by thrombolysis or mechanical), GIK did not show beneficial effects. 
Table 2 Study outcomes and glycaemic parameters

\begin{tabular}{|c|c|c|c|c|c|c|c|c|c|c|c|}
\hline \multirow[t]{2}{*}{ Study } & \multirow[t]{2}{*}{ Treatment } & \multirow[t]{2}{*}{ Patients } & \multirow[t]{2}{*}{$\begin{array}{l}\text { Glucose target } \\
\text { range }(\mathrm{mmol} / \mathrm{l})\end{array}$} & \multicolumn{2}{|c|}{$\begin{array}{l}\text { Glucose level } \\
(\mathrm{mmol} / \mathrm{l} \pm \mathrm{SD})\end{array}$} & \multicolumn{3}{|c|}{ Mortality (\%) } & \multicolumn{3}{|c|}{ Long-term mortality } \\
\hline & & & & Admission & $\begin{array}{l}16- \\
24 \mathrm{~h}\end{array}$ & $\begin{array}{l}30- \\
40 \text { days }\end{array}$ & $\mathrm{HR}(95 \% \mathrm{CI})$ & $P$ & $\%$ & Months & $P$ \\
\hline \multirow[t]{2}{*}{ Fath et al. [31] } & Control & 972 & & & & 21 & & & & & \\
\hline & GIK & 956 & & & & 16 & $0.76(0.6-0.9)$ & 0.004 & - & & \\
\hline \multirow[t]{2}{*}{ Pol-GIK } & Control & 460 & - & 7 & 6.2 & 4.8 & & & 6.5 & & \\
\hline & GIK & 494 & $<16.8$ & 6.9 & 5.9 & 8.9 & $1.85(1.1-3.1)$ & 0.01 & 11.1 & 6 & 0.01 \\
\hline \multirow{2}{*}{$\begin{array}{l}\text { Krljanac } \\
\text { et al. [32] }\end{array}$} & Control & 40 & - & & & $10.0^{\mathrm{b}}$ & & & 4.0 & & \\
\hline & GIK & 78 & - & & & $3.0^{\mathrm{b}}$ & $0.30(0.0-1.4)$ & 0.08 & 10.0 & 12 & 0.18 \\
\hline \multirow[t]{2}{*}{ GIPS I } & Control & 464 & - & 8.5 & 8.1 & 5.8 & & & 8.2 & & \\
\hline & GIK & 476 & $7.0-11.0$ & 8.5 & 7.7 & 4.8 & $0.83(0.5-1.4)$ & 0.50 & 6.5 & 12 & 0.32 \\
\hline \multirow[t]{2}{*}{ GIPS II } & Control & 445 & - & $8.3 \pm 2.5$ & - & 1.8 & & & 3.9 & & \\
\hline & GIK & 444 & - & $8.5 \pm 2.8$ & - & 2.9 & $1.61(0.7-3.8)$ & 0.27 & 5.3 & 12 & 0.33 \\
\hline \multirow[t]{2}{*}{ Create-ECLA } & Control & 10,107 & - & 9.0 & 7.5 & 9.7 & & & - & & \\
\hline & GIK & 10,088 & - & 9.0 & 8.6 & 10 & $1.03(0.9-1.1)$ & 0.45 & - & & \\
\hline \multirow[t]{2}{*}{ OASIS 6} & Control & 1374 & - & & & 6.7 & & & 10.4 & & \\
\hline & GIK & 1374 & - & & & 7.6 & $1.13(0.9-1.5)$ & 0.36 & 10.8 & 6 & NS \\
\hline \multirow[t]{2}{*}{ DIGAMI I } & Control & 314 & & $15.7 \pm 4.2$ & $11.7 \pm 4.1$ & 15.6 & & & 26.1 & & \\
\hline & $\begin{array}{l}\text { Insulin } 24 \mathrm{~h}+ \\
3 \text { months SC }\end{array}$ & 306 & $7.0-10$ & $15.4 \pm 4.1$ & $9.6 \pm 3.3$ & 12.4 & $0.79(0.5-1.2)$ & NS & 18.6 & 12 & 0.027 \\
\hline \multirow[t]{3}{*}{ DIGAMI II } & Standard practice & 306 & & $12.9 \pm 4.6$ & $10.0 \pm 3.6$ & 7.5 & & & 17 & & \\
\hline & $\begin{array}{l}\text { Insulin } 24 \mathrm{~h}+ \\
3 \text { months SC }\end{array}$ & 474 & $\begin{array}{l}7.0-10.0+ \\
\text { fasting } 5.0-7.0\end{array}$ & $12.8 \pm 4.5$ & $9.1 \pm 3.0$ & 7.5 & $1.00(0.6-1.7)$ & NS & 15 & & \\
\hline & Insulin $24 \mathrm{~h}$ & 473 & $7.0-10.0$ & $12.5 \pm 4.4$ & $9.1 \pm 2.8$ & 7.5 & $1.00(0.6-1.6)$ & NS & 12 & 12 & NS \\
\hline \multirow[t]{2}{*}{ HI-5 } & Control & 114 & & $11.1 \pm 3.5$ & $9.0 \pm 2.8^{\mathrm{a}}$ & $7.1^{\mathrm{c}}$ & & & 7.9 & & \\
\hline & Insulin/dextrose & 126 & $4.0-10.0$ & $10.8 \pm 4.1$ & $8.3 \pm 2.2^{\mathrm{a}}$ & $4.4^{\mathrm{c}}$ & $0.62(0.2-1.8)$ & 0.42 & 6.1 & 6 & 0.62 \\
\hline
\end{tabular}

$S D$ standard deviation, $H R$ hazard ratio, $C I$ confidence interval, $N S$ not statistically significant, $G I K$ glucose-insulin-potassium, $S C$ subcutaneous insulin

${ }^{\mathrm{a}}$ Mean glucose over $24 \mathrm{~h}$

${ }^{\mathrm{b}}$ Cardiac mortality

${ }^{\mathrm{c}}$ Mortality at 3 months

The early randomised trials which were performed between 1994 and 2004 varied in size from 118 [32] to 20,195 [33] and included patients in Europe [32, 34, 35] and other continents [36, 37]. Reperfusion therapy was given as thrombolysis or primary percutaneous coronary intervention in less than $1 \%$ [31] to $100 \%$ of patients enrolled [32]. Admission glucose values, when reported, varied from 6.9 to $9 \mathrm{mmol} / \mathrm{l}$ and were similar across control and GIK groups. All-cause mortality at 30-40 days was higher in the GIK group in four of the six studies (reaching statistical significance in Pol-GIK). In three studies that reported longer follow-up (6-12 months) the mortality difference in favour of the control group remained (also reaching statistical significance in Pol-GIK). Two studies showed a trend in cardiac [32] and all-cause (GIPS) mortality in favour of GIK, though these did not reach statistical significance. Because in GIPS a subgroup of patients without heart failure had a lower 30-day mortality in the GIK-treated group ( $1.2 \%$ vs. $4.2 \%, P=0.01)$, GIPS2 was set up excluding patients with symptoms of heart failure, but this study did not show any beneficial effect of GIK [34].

The differences in effect of GIK between the earlier and more recent studies can be explained by improvements in treatment (including reperfusion, antiplatelet and $\beta$-blocker therapy), which is reflected in the lower mortality rates of the studies performed after 1987. In the more recent studies all 30-40 day mortality rates were below $16 \%$, which is the mortality rate of GIK-treated patients in the meta-analysis of trials from 1965 to 1987.

A parallel could be drawn between GIK and the administration of intravenous magnesium in AMI patients; 
promising beneficial effects in smaller studies were not confirmed in the large randomised MAGIC trial and the concept was abandoned [38].

\section{Conclusions}

Insulin treatment in AMI patients has been investigated extensively. The concept of systematic GIK in patients with elevated or normal glucose levels was not supported by recent trials in the reperfusion era and has been abandoned.

IGL targeted to achieve normoglycaemia can improve survival and reduce incidence of adverse events. However, achievement of glucose regulation is difficult and carries the risk of hypoglycaemia. More research is needed to investigate the role of computerised insulin protocols and continuous glucose sensors to improve safety and efficacy of IGL.

Open Access This article is distributed under the terms of the Creative Commons Attribution Noncommercial License which permits any noncommercial use, distribution, and reproduction in any medium, provided the original author(s) and source are credited.

\section{References}

1. Rydén L, Standl E, Bartnik M, et al. Guidelines on diabetes, prediabetes, and cardiovascular diseases: executive summary. The Task Force on Diabetes and Cardiovascular Diseases of the European Society of Cardiology (ESC) and of the European Association for the Study of Diabetes (EASD). Eur Heart J. 2007;28(1):88-136.

2. Beck JA, Meisinger C, Heier M, et al. Effect of blood glucose concentrations on admission in non-diabetic versus diabetic patients with first acute myocardial infarction on short- and long-term mortality (from the MONICA/KORA Augsburg Myocardial Infarction Registry). Am J Cardiol. 2009;104(12):160712.

3. Capes SE, Hunt D, Malmberg K, et al. Stress hyperglycaemia and increased risk of death after myocardial infarction in patients with and without diabetes: a systematic overview. Lancet. 2000;355 (9206):773-8.

4. Norhammar A, Tenerz $\AA$, Nilsson G, et al. Glucose metabolism in patients with acute myocardial infarction and no previous diagnosis of diabetes mellitus: a prospective study. Lancet. 2002;359(9324):2140-4.

5. Lenzen M, Ryden L, Ohrvik J, et al. Diabetes known or newly detected, but not impaired glucose regulation, has a negative influence on 1-year outcome in patients with coronary artery disease: a report from the Euro Heart Survey on diabetes and the heart. Eur Heart J. 2006;27(24):2969-74.

6. Tansey MJ, Opie LH. Relation between plasma free fatty acids and arrhythmias within the first twelve hours of acute myocardial infarction. Lancet. 1983;2(8347):419-22.

7. Oliver MF. Metabolic causes and prevention of ventricular fibrillation during acute coronary syndromes. Am J Med. 2002;112(4):305-11.

8. Hansen TK, Thiel S, Wouters PJ, et al. Intensive insulin therapy exerts antiinflammatory effects in critically ill patients and counter- acts the adverse effect of low mannose-binding lectin levels. J Clin Endocrinol Metab. 2003;88(3):1082-8.

9. Steinberg HO, Brechtel G, Johnson A, et al. Insulin-mediated skeletal muscle vasodilation is nitric oxide dependent. A novel action of insulin to increase nitric oxide release. J Clin Invest. 1994;94(3):1172-9.

10. Dandona P, Aljada A, Bandyopadhyay A. The potential therapeutic role of insulin in acute myocardial infarction in patients admitted to intensive care and in those with unspecified hyperglycemia. Diab Care. 2003;26(2):516-9.

11. Malmberg K, Rydén L, Efendic S, et al. Randomized trial of insulin-glucose infusion followed by subcutaneous insulin treatment in diabetic patients with acute myocardial infarction (DIGAMI study): effects on mortality at 1 year. J Am Coll Cardiol. 1995;26(1):57-65.

12. Furnary AP, Gao G, Grunkemeier GL, et al. Continuous insulin infusion reduces mortality in patients with diabetes undergoing coronary artery bypass grafting. J Thorac Cardiovasc Surg. 2003;125(5):1007-21.

13. Van den Berghe G, Wouters P, Weekers F, et al. Intensive insulin therapy in critically Ill patients. N Engl J Med. 2001;345 (19):1359-67.

14. Weston C, Walker L, Birkhead J. Early impact of insulin treatment on mortality for hyperglycaemic patients without known diabetes who present with an acute coronary syndrome. Heart. 2007;93(12):1542-6.

15. Anselmino M, Ohrvik J, Malmberg K, et al. Glucose lowering treatment in patients with coronary artery disease is prognostically important not only in established but also in newly detected diabetes mellitus: a report from the Euro Heart Survey on Diabetes and the Heart. Eur Heart J. 2008;29(2):177-84.

16. Malmberg K, Rydén L, Wedel H, et al. Intense metabolic control by means of insulin in patients with diabetes mellitus and acute myocardial infarction (DIGAMI 2): effects on mortality and morbidity. Eur Heart J. 2005;26(7):650-61.

17. Cheung NW, Wong VW, McLean M. The Hyperglycemia: intensive insulin infusion in infarction (HI-5) study: a randomized controlled trial of insulin infusion therapy for myocardial infarction. Diab Care. 2006;29(4):765-70.

18. Sodi-Pallares D, Bisteni A, Medrano GA, et al. The polarizing treatment of acute myocardial infarction. Possibility of its use in other cardiovascular conditions. Dis Chest. 1963;43:424-32.

19. Sodi-Pallares D, Testelli MR, Fishleder BL, et al. Effects of an intravenous infusion of a potassium-glucose-insulin solution on the electrocardiographic signs of myocardial infarction. A preliminary clinical report. Am J Cardiol. 1962;9:166-81.

20. Clark RS, English M, McNeill GP, et al. Effect of intravenous infusion of insulin in diabetics with acute myocardial infarction. Br Med J (Clin Res Ed). 1985;291(6491):303-5.

21. Gwilt DJ, Petri M, Lamb P, et al. Effect of intravenous insulin infusion on mortality among diabetic patients after myocardial infarction. Br Heart J. 1984;51(6):626-30.

22. Wiener RS, Wiener DC, Larson RJ. Benefits and risks of tight glucose control in critically Ill adults: a meta-analysis. JAMA. 2008;300(8):933-44.

23. Kushner FG, Hand M, Smith SC, et al. Focused updates: ACC/ AHA Guidelines for the Management of Patients With STElevation Myocardial Infarction (Updating the 2004 Guideline and 2007 Focused Update) and ACC/AHA/SCAI Guidelines on Percutaneous Coronary Intervention (Updating the 2005 Guideline and 2007 Focused Update). A Report of the American College of Cardiology Foundation/American Heart Association Task Force on Practice Guidelines. Circulation [Internet]. 2009 Nov 18 [cited 2009 Dec 1]. Available at: http://www.ncbi.nlm.nih. gov/pubmed/19923169

24. Van de Werf F, Bax J, Betriu A, et al. Management of acute myocardial infarction in patients presenting with persistent ST- 
segment elevation: the task force on the management of ST-segment elevation acute myocardial infarction of the European society of cardiology. Eur Heart J. 2008;29(23):2909-45.

25. Meijering S, Corstjens A, Tulleken J, et al. Towards a feasible algorithm for tight glycaemic control in critically ill patients: a systematic review of the literature. Crit Care. 2006;10(1):R19.

26. Lipton JA, Barendse, Eenkhoorn, et al. Glucose control as a model for implementation of a clinical decision support system [Internet]. [cited 2009 Mar 11]. Available at: http://www.cinc.org/ Proceedings/2008/pdf/0661.pdf

27. Vogelzang M, Loef BG, Regtien JG, et al. Computer-assisted glucose control in critically ill patients. Intensive Care Med. 2008;34(8):1421-7.

28. Rood E, Bosman RJ, van der Spoel JI, et al. Use of a computerized guideline for glucose regulation in the intensive care unit improved both guideline adherence and glucose regulation. J Am Med Inform Assoc. 2005;12(2):172-80.

29. Wong X, Chase J, Shaw G, et al. Model predictive glycaemic regulation in critical illness using insulin and nutrition input: a pilot study. Med Eng Phys. 2006;28(7):665-81.

30. Vriesendorp TM, DeVries JH, Holleman F, et al. The use of two continuous glucose sensors during and after surgery. Diabetes Technol Ther. 2005;7(2):315-22.

31. Fath-Ordoubadi F, Beatt KJ. Glucose-insulin-potassium therapy for treatment of acute myocardial infarction: an overview of randomized placebo-controlled trials. Circulation. 1997;96(4):1152-6.

32. Krljanac G, Vasiljevic Z, Radovanovic M, et al. Effects of glucose-insulin-potassium infusion on ST-elevation myocardial infarction in patients treated with thrombolytic therapy. Am J Cardiol. 2005;96(8):1053-8.

33. Mehta SR, Yusuf S, Díaz R, et al. Effect of glucose-insulinpotassium infusion on mortality in patients with acute ST-segment elevation myocardial infarction: the CREATE-ECLA randomized controlled trial. JAMA. 2005;293(4):437-46.

34. van der Horst ICC, Timmer JR, Ottervanger JP, et al. Glucoseinsulin-potassium and reperfusion in acute myocardial infarction: rationale and design of the Glucose-Insulin-Potassium Study-2 (GIPS-2). Am Heart J. 2005;149(4):585-91.

35. Ceremuzyński L, Budaj A, Czepiel A, et al. Low-dose glucoseinsulin-potassium is ineffective in acute myocardial infarction: results of a randomized multicenter Pol-GIK trial. Cardiovasc Drugs Ther. 1999;13(3):191-200.

36. Yusuf S, Mehta SR, Chrolavicius S, et al. Effects of fondaparinux on mortality and reinfarction in patients with acute ST-segment elevation myocardial infarction: the OASIS- 6 randomized trial. JAMA. 2006;295(13):1519-30.

37. Yusuf S, Mehta SR, Díaz R, et al. Challenges in the conduct of large simple trials of important generic questions in resource-poor settings: the CREATE and ECLA trial program evaluating GIK (glucose, insulin and potassium) and low-molecular-weight heparin in acute myocardial infarction. Am Heart J. 2004;148 (6):1068-78.

38. Antman E. Early administration of intravenous magnesium to high-risk patients with acute myocardial infarction in the Magnesium in Coronaries (MAGIC) Trial: a randomised controlled trial. Lancet. 2002;360(9341):1189-96. 